\title{
Cholesterol metabolism, transport, and hepatic regulation in dairy cows during transition and early lactation
}

\author{
E. C. Kessler, ${ }^{*}$ J. J. Gross, ${ }^{*}$ R. M. Bruckmaier, ${ }^{*}$ and C. Albrecht $+\ddagger^{1}$ \\ *Veterinary Physiology, Vetsuisse Faculty, and \\ †Institute of Biochemistry and Molecular Medicine, University of Bern, CH-3012 Bern, Switzerland \\ $\ddagger$ Swiss National Center of Competence in Research (NCCR) TransCure, University of Bern, CH-3012 Bern, Switzerland
}

\section{ABSTRACT}

The transition from the nonlactating to the lactating state represents a critical period for dairy cow lipid metabolism because body reserves have to be mobilized to meet the increasing energy requirements for the initiation of milk production. The purpose of this study was to provide a comprehensive overview on cholesterol homeostasis in transition dairy cows by assessing in parallel plasma, milk, and hepatic tissue for key factors of cholesterol metabolism, transport, and regulation. Blood samples and liver biopsies were taken from 50 multiparous Holstein dairy cows in wk 3 antepartum (a.p.), wk 1 postpartum (p.p.), wk 4 p.p., and wk 14 p.p. Milk sampling was performed in wk 1, 4, and 14 p.p. Blood and milk lipid concentrations [triglycerides (TG), cholesterol, and lipoproteins], enzyme activities (phospholipid transfer protein and lecithin:cholesterol acyltransferase) were analyzed using enzymatic assays. Hepatic gene expression patterns of 3-hydroxy3-methylglutaryl-coenzyme A (HMGC) synthase 1 (HMGCS1) and HMGC reductase $(H M G C R)$, sterol regulatory element-binding factor $(S R E B F)-1$ and -2, microsomal triglyceride transfer protein $(M T T P)$, ATPbinding cassette transporter $(A B C) A 1$ and $A B C G 1$, liver $\mathrm{X}$ receptor $(L X R) \alpha$ and peroxisome proliferator activated receptor $(P P A R) \alpha$ and $\gamma$ were measured using quantitative RT-PCR. Plasma TG, cholesterol, and lipoprotein concentrations decreased from wk 3 a.p. to a minimum in wk 1 p.p., and then gradually increased until wk 14 p.p. Compared with wk 4 p.p., phospholipid transfer protein activity was increased in wk 1 p.p., whereas lecithin:cholesterol acyltransferase activity was lowest at this period. Total cholesterol concentration and mass, and cholesterol concentration in the milk fat fraction decreased from wk 1 p.p. to wk 4 p.p. Both total and milk fat cholesterol concentration were decreased in wk 4 p.p. compared with wk 1

Received January 9, 2014

Accepted May 7, 2014.

${ }^{1}$ Corresponding author: christiane.albrecht@ibmm.unibe.ch and 14 p.p. The mRNA abundance of genes involved in cholesterol synthesis (SREBF-2, HMGCS1, and $H M G C R)$ markedly increased from wk 3 a.p. to wk 1 p.p., whereas $S R E B F-1$ was downregulated. The expression of $A B C A 1$ increased from wk 3 a.p. to wk 1 p.p., whereas $A B C G 1$ was increased in wk 14 p.p. compared with other time points. In conclusion, hepatic expression of genes involved in the biosynthesis of cholesterol as well as the $A B C A 1$ transporter were upregulated at the onset of lactation, whereas plasma concentrations of total cholesterol, phospholipids, lipoprotein-cholesterol, and TG were at a minimum. Thus, at the gene expression level, the liver seems to react to the increased demand for cholesterol after parturition. Whether the low plasma cholesterol and TG levels are due to impaired hepatic export mechanisms or reflect an enhanced transfer of these compounds into the milk to provide essential nutrients for the newborn remains to be elucidated.

Key words: cholesterol metabolism, lipoprotein, dairy cow

\section{INTRODUCTION}

Cholesterol and lipid metabolism have been widely investigated in humans and in rodent animal models as important factors contributing to lipid-associated diseases, such as atherosclerosis or Tangier disease (Maxfield and Tabas, 2005). In dairy cows, an important lipid-related metabolic disorder is fatty liver (Grummer, 1993). Particularly during the periparturient period lipid metabolism is challenged to ensure the increasing energy demands. Thus, adipose tissue is mobilized and the liver has to cope with an increasing supply of NEFA either by oxidation or by reesterification to triglycerides (TG; Grummer, 1993). Fatty liver develops when TG synthesis exceeds the export of TG as very low density lipoproteins (VLDL; Goff and Horst, 1997).

Lipoproteins are composed of a core of hydrophobic lipids (TG and cholesteryl esters) and an envelope constituted of apoproteins and amphiphilic lipids (phospholipids and free cholesterol). Hepatocytes secrete 
cholesterol and TG in VLDL, which are processed in the circulation into intermediate-density lipoproteins by hydrolysis of the triglycerides. Intermediate-density lipoproteins are rich in cholesteryl esters and are either metabolized to low density lipoproteins (LDL) or taken up by the liver. In humans, LDL are the main carriers of cholesterol in blood and deliver cholesterol from the liver to the peripheral tissues. Cholesterol is returned from extrahepatic tissues to the liver in high density lipoproteins (HDL) by reverse cholesterol transport.

Selective aspects of cholesterol metabolism in dairy cows have been a matter of intense investigation. Thus, bovine serum lipids and lipoproteins during gestation and lactation have been determined (Raphael et al., 1973; Puppione et al., 1980) as well as the percentage of cholesterol in milk (Bitman and Wood, 1990). Genes involved in cholesterol synthesis, such as 3-hydroxy3-methylglutaryl-CoA reductase (HMGCR) and 3-hydroxy-3-methylglutaryl-CoA synthase (HMGCS), and the regulation of the latter by sterol regulatory element-binding proteins (SREBP) in dairy cows have been recently assessed (Viturro et al., 2009; Schlegel et al., 2012). However, in those studies, only specific parameters of the complex network of cholesterol metabolism were selectively highlighted or analysis was restricted to specific compartments (e.g., plasma), or both. Moreover, potential associations between the hepatic activity and resulting effects on both plasma and milk cholesterol levels have been neglected so far.

Therefore, the purpose of the present study was to give a comprehensive overview of cholesterol metabolism, transport, and hepatic regulatory genes in dairy cows during the transition period and until mid lactation at different regulatory and functional levels. To get insights into potential interactions between the liver and the mammary gland, plasma and milk cholesterol contents were assessed in parallel in relation to endocrine factors, enzyme activities, and hepatic gene expressions of regulatory factors and enzymes.

\section{MATERIALS AND METHODS}

\section{Animal Trial}

The animal experiments were carried out at the Agricultural Experimental Unit Hirschau of the Technical University of Munich (Munich, Germany) and were approved by the responsible department for animal welfare affairs. Fifty multiparous Holstein dairy cows (parity $3.2 \pm 0.2$; mean $\pm \mathrm{SEM}$ ) were studied during a period from wk 3 antepartum (a.p.) to wk 14 postpartum (p.p.). Cows were fed a mixed ration based on hay, grass, and corn silage for ad libitum intake and additional cereal-based concentrate according to milk production. The energy content of the mixed ration was $6.53 \pm 0.08$ and $7.96 \pm 0.04 \mathrm{MJ}$ of $\mathrm{NE}_{\mathrm{L}} / \mathrm{kg}$ of $\mathrm{DM}$ for the concentrates, respectively. The partial mixed ration had a crude fat content of $32 \pm 6$ and concentrates of $24 \pm 6 \mathrm{~g} / \mathrm{kg}$ of DM, respectively. Details on the animal trial and the feeding regimen were described previously (Gross et al., 2011a).

\section{Blood and Milk Sampling}

Blood samples were collected from the jugular vein between 0730 and $0900 \mathrm{~h}$ before feeding in wk 3 a.p., wk 1 p.p., wk 4 p.p., and wk 14 p.p. The EDTA blood samples were immediately cooled down on wet ice, centrifuged at $2,000 \times g$ for 15 min at $4^{\circ} \mathrm{C}$ and then aliquoted. Plasma samples were stored at $-20^{\circ} \mathrm{C}$ until analysis.

Morning milk samples were collected once weekly at $0500 \mathrm{~h}$ in wk 1 p.p., wk 4 p.p., and wk 14 p.p. and stored at $-20^{\circ} \mathrm{C}$ until analysis.

\section{Plasma Lipids}

Concentrations of total cholesterol (TC) and TG were measured with enzymatic kits from bioMérieux SA (Geneva, Switzerland; no. 61219 for TC; no. 61236 for TG). Concentrations of phospholipids (PL) and free cholesterol (FC) were measured with enzymatic kits from Wako Pure Chemical Industries Ltd. (Osaka, Japan; no. 296-63801 for PL; no. 435-35801 for FC). High density lipoprotein cholesterol (HDL-C) was measured with an immunoinhibition method (kit no. 412-72395) and LDL cholesterol (LDL-C) with an enzymatic kit (no. 419-24017) from Wako Chemical GmbH (Neuss, Germany).

Concentrations of cholesteryl esters (CE), VLDL cholesterol (VLDL-C), and LDL-C were calculated using the following equations:

$$
\text { Cholesteryl esters }=\text { total cholesterol }
$$$$
\text { - free cholesterol; }
$$

VLDL-C = triglycerides $/ 5$ (Friedewald et al., 1972);

$$
\begin{gathered}
\text { LDL-C }=\text { total cholesterol }-(\text { HDL-C } \\
+ \text { triglycerides } / 5) \text { (Friedewald et al., 1972). }
\end{gathered}
$$

The LDL-C was additionally measured with an enzymatic kit (no. 419-24017) from Wako Chemical GmbH. The correlation between enzymatically measured and calculated LDL-C was $0.99(P<0.001)$. 


\section{Plasma Enzyme Activities}

Lecithin:cholesterol acyltransferase (LCAT) and phospholipid transfer protein (PLTP) activities in plasma were measured with fluorescence activity assays from Roar Biomedical Inc. (New York, NY; no. RB-LCAT; no. P7700) according to the manufacturer's instructions. The LCAT activity is expressed as the ratio of the emissions of the substrate hydrolyzed to that not hydrolyzed.

\section{Milk Cholesterol}

Raw milk samples were thawed in a water bath and then put in an ultrasound bath for 5 min for homogenization. The methods described in Paradkar and Irudayaraj (2002) and Kamelska et al. (2012) were modified as follows: $9 \mathrm{~mL}$ of ethanol and $1 \mathrm{~mL}$ of $\mathrm{KOH}(8.9$ $M \mathrm{KOH}$ solution) were added to $2 \mathrm{~mL}$ of raw milk and the mixture was vortexed for $20 \mathrm{~s}$. Then, the capped test tube was placed in a water bath at $60^{\circ} \mathrm{C}$, saponified, and stirred continuously at $200 \mathrm{rpm}$ for $1 \mathrm{~h}$. After cooling to room temperature, $5 \mathrm{~mL}$ of deionized water and $10 \mathrm{~mL}$ of hexane were added and vortexed for approximately $2 \mathrm{~min}$. The sample was then centrifuged at $2,500 \times g$ for $3 \mathrm{~min}$ at $4^{\circ} \mathrm{C}$ and the upper hexane layer was transferred into a new vial. The extraction process (10 $\mathrm{mL}$ of hexane) and centrifugation step $\left(2,500 \times g\right.$ for $3 \mathrm{~min}$ at $\left.4^{\circ} \mathrm{C}\right)$ were repeated, and the upper hexane layer was also transferred into the test tube. The hexane extract was evaporated to dryness in a water bath at $70^{\circ} \mathrm{C}$ and the sample was redissolved in $2 \mathrm{~mL}$ of isopropanol. Total and free cholesterol in milk were measured with enzymatic kits (no. 61219 for TC) from bioMérieux SA and from Wako Pure Chemical Industries Ltd. (no. 435-35801 for FC) according to the manufacturers' protocols.

\section{Milk Fat Content}

Milk fat concentrations were measured using an infrared analyzer (MilkoScan FT-6000; Foss Analytical A/S, Hillerød, Denmark) by the Milchprüfring Bayern e.V. (Wolnzach, Germany).

\section{Liver Tissue Sampling and Hepatic Gene Expression}

The liver was biopsied in parallel with blood sampling in wk 3 a.p., wk 1 p.p., wk 4 p.p., and wk 14 p.p. under local anesthesia by needle biopsy as described by Gross et al. (2011b). Liver samples were put in RNA stabilization reagent (RNAlater; Ambion, Applied Biosystems Inc., Austin, TX), kept at $+4^{\circ} \mathrm{C}$ for $24 \mathrm{~h}$, and then stored at $-20^{\circ} \mathrm{C}$ until analysis. Ribonucleic acid isolation was performed with peqGOLD TriFast reagent (PEQLAB Biotechnologie GmbH, Erlangen, Germany). The RNA integrity was verified by the optical density (OD) ratio at wavelengths of 260 and 280 $\mathrm{nm}$. All samples had an $\mathrm{OD}_{260}: \mathrm{OD}_{280}$ absorption ratio between 1.7 and 2.1. After reverse transcription of 1 $\mu \mathrm{g}$ of total RNA into cDNA, PCR quantification of ATP-binding cassette transporter $(\boldsymbol{A B C}) A 1, A B C G 1$, $H M G C R, H M G C S 1$, liver $\mathrm{X}$ receptor $\alpha(\boldsymbol{L} \boldsymbol{X} \boldsymbol{R} \boldsymbol{\alpha})$, microsomal triglyceride transfer protein $(\boldsymbol{M T T P})$, peroxisome proliferator-activated receptor $(\boldsymbol{P P A R})$ $\alpha$ and $\gamma$, and sterol regulatory element-binding factor ( $\boldsymbol{S R E B F}$-1 and SREBF-2 genes was performed. Previous studies covering different metabolic stages in dairy cows showed that GAPDH and ubiquitin were stably expressed in the liver during the experiment (van Dorland et al., 2009; Graber et al., 2010; Gross et al., 2011b, 2013) and, thus, the mRNA abundance of the target genes was calculated in relation to their expression. The sizes of the obtained PCR products were verified on a gel. Details regarding the primers for the measured genes and methods used are given in Table 1 and in Gross et al. (2011b).

\section{Statistical Analysis}

Data presented in text and figures are means \pm standard error of the means (SEM). The correlation between measured and calculated LDL cholesterol was evaluated with PROC CORR of SAS (version 9.2; SAS Institute Inc., Cary, NC).

To evaluate changes over time, data on plasma parameters, milk cholesterol, and hepatic mRNA abundances at the respective time points in wk 3 a.p., wk 1 p.p., wk 4 p.p., and wk 14 p.p. were evaluated by a MIXED model in SAS, with time point and parity as fixed effects. Differences over time were detected by the Bonferroni $t$-test at $P<0.05$.

\section{RESULTS}

\section{Plasma Lipids}

The plasma concentrations of TC, CE, FC, PL, LDL$\mathrm{C}$, and HDL-C $(2.53 \pm 0.06,1.81 \pm 0.05,0.72 \pm 0.02$, $1.31 \pm 0.03,1.40 \pm 0.04$, and $1.19 \pm 0.02 \mathrm{mmol} / \mathrm{L}$, respectively) decreased from wk 3 a.p. to a nadir in wk 1 p.p. $(1.59 \pm 0.05,1.06 \pm 0.04,0.53 \pm 0.01,0.96 \pm 0.03$, $0.69 \pm 0.02$, and $0.93 \pm 0.03 \mathrm{mmol} / \mathrm{L}$, respectively) and increased thereafter steadily until a maximum in wk 14 p.p. $(4.91 \pm 0.12,3.69 \pm 0.09,1.22 \pm 0.03,2.43 \pm 0.05$, $2.86 \pm 0.09$, and $2.05 \pm 0.04 \mathrm{mmol} / \mathrm{L}$, respectively; Figures $1 \mathrm{~A}-\mathrm{C})$. 
Table 1. Nucleotide and PCR product specifications

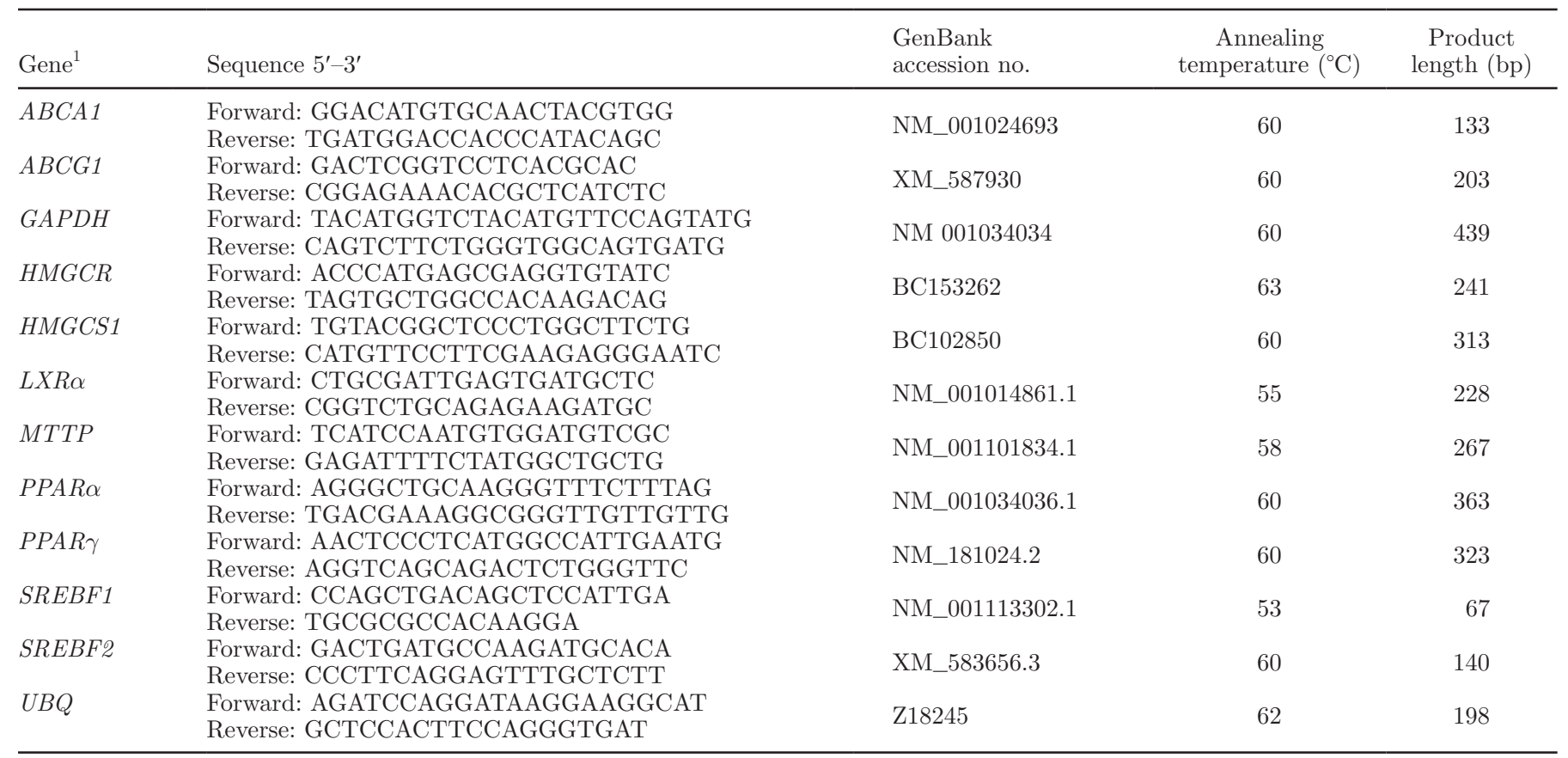

${ }^{1} A B C A 1=$ ATP-binding cassette transporter A1; $A B C G 1=$ ATP-binding cassette transporter G1; $H M G C R=3$-hydroxy-3-methylglutaryl-CoA reductase; $H M G C S 1=3$-hydroxy-3-methylglutaryl-CoA synthase $1 ; L X R \alpha=$ liver X receptor $\alpha ; M T T P=$ microsomal triglyceride transfer protein; PPAR $\alpha=$ peroxisome proliferator-activated receptor $\alpha ; P P A R \gamma=$ peroxisome proliferator-activated receptor $\gamma ; S R E B F-1=$ sterol regulatory element-binding factor $1 ; S B R E F-2=$ sterol regulatory element-binding factor $2 ; U B Q=$ ubiquitin.

The concentrations of TG and VLDL-C in plasma decreased from a maximum in wk 3 a.p. $(0.22 \pm 0.01$ and $0.044 \pm 0.001 \mathrm{mmol} / \mathrm{L}$, respectively) to a minimum in wk 1 p.p. $(0.11 \pm 0.00$ and $0.022 \pm 0.001 \mathrm{mmol} / \mathrm{L}$, respectively; Figures $1 \mathrm{~B}$ and $1 \mathrm{C})$. After parturition, the TG and VLDL-C concentrations increased steadily from wk 1 p.p. to wk 14 p.p. $(0.13 \pm 0.00$ and 0.026 $\pm 0.001 \mathrm{mmol} / \mathrm{L}$, respectively). The plasma concentrations of measured and calculated LDL-C were highly correlated ( $\mathrm{r}=0.99 ; P<0.001$; data not shown).

Parity had a significant effect on plasma cholesterol (TC, FC, LDL-C, HDL-C, and CE) and PL concentrations $(P<0.0001)$. Cows with parity 2 and 3 had higher values for TC, FC, LDL-C, HDL-C, CE, and PL compared with cows with parity $\geq 4$. All other factors determined in this study were not significantly affected by parity.

\section{Plasma Enzyme Activities}

Compared with the other time points, the plasma LCAT activity was lowest in wk 1 p.p. (ratio of $2.44 \pm$ 0.07 ; Figure 2). In contrast, the PLTP activity was elevated in wk 1 p.p. $(45.67 \pm 2.80 \mathrm{pmol})$ and decreased thereafter until wk 14 p.p. $(31.32 \pm 1.37$ pmol; Figure 2 ). Interestingly, the plasma activity of PLTP and LCAT showed an inverse pattern.

\section{Milk Cholesterol}

The concentration of TC in milk decreased from wk 1 p.p. $(0.32 \pm 0.03 \mathrm{mmol} / \mathrm{L})$ to wk 4 p.p. $(0.18 \pm 0.02$ $\mathrm{mmol} / \mathrm{L})$ and increased by trend in wk 14 p.p. $(0.27$ $\pm 0.02 \mathrm{mmol} / \mathrm{L})$ to a lower concentration than in wk 1 p.p. $(P=0.084$; Figure $3 \mathrm{~A})$. The FC in milk followed the pattern and concentration of TC, indicating that cholesterol in milk represents mostly FC (data not shown). The TC mass in milk was highest in wk 1 p.p. $(2.26 \pm 0.19 \mathrm{~g})$ and decreased thereafter in wk 4 p.p. $(1.55 \pm 0.13 \mathrm{~g}$; Figure $3 \mathrm{~A})$. In wk 14 p.p., the TC mass in milk increased by trend $(1.88 \pm 0.09 \mathrm{~g} ; P=0.066)$.

Cholesterol concentration in the milk fat fraction (mg of cholesterol per $100 \mathrm{~g}$ of fat) decreased from wk 1 p.p. $(248.33 \pm 18.27 \mathrm{mg}$ of cholesterol/100 g of fat) to a minimum in wk 4 p.p. (171.55 $\pm 14.67 \mathrm{mg}$ of cholesterol/100 $\mathrm{g}$ of fat) and increased thereafter in wk 14 p.p. $(272.35 \pm 9.90 \mathrm{mg}$ of cholesterol/100 g of fat; Figure 3B). Milk fat mass did not change from wk 1 p.p. $(919.53 \pm 52.05 \mathrm{~g})$ to wk 4 p.p. $(937.93 \pm 56.33 \mathrm{~g})$, but decreased in wk 14 p.p. (687.35 \pm 24.47 g; Figure 3B).

\section{Hepatic Gene Expression}

The results of the gene expression measurements are summarized in Table 2. The expression of $A B C A 1$ 

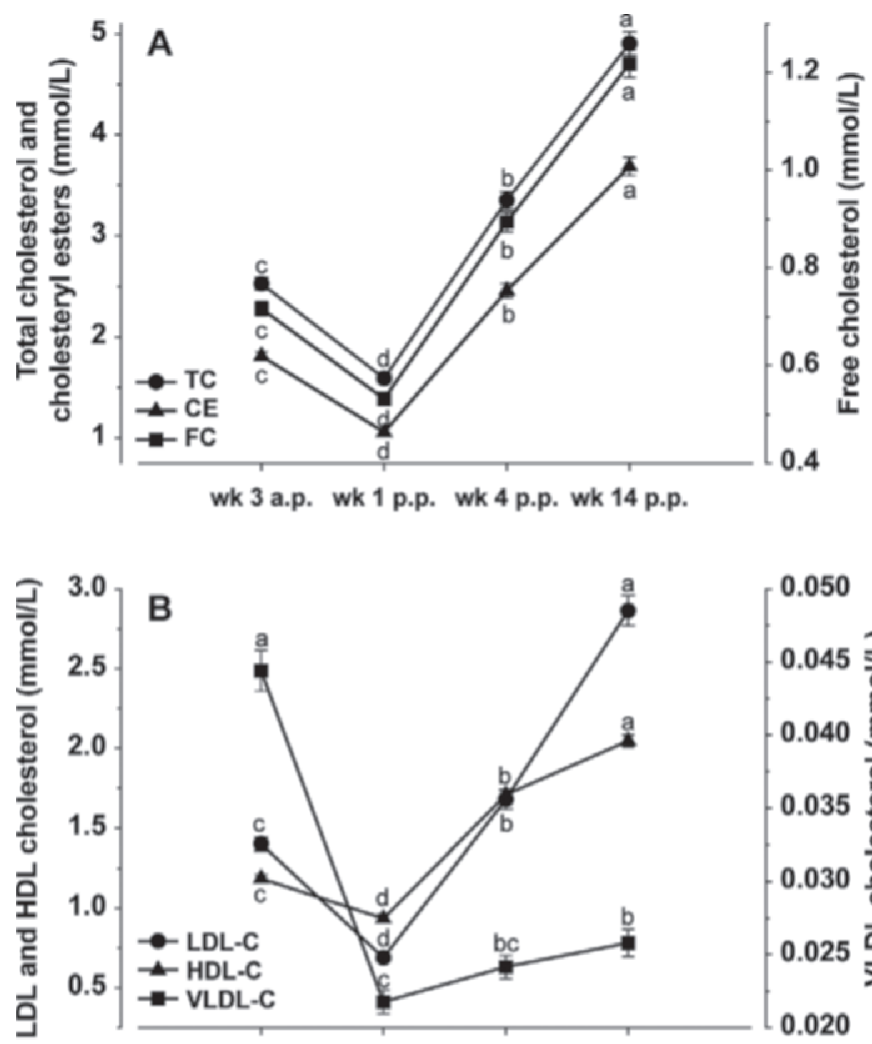

wk 3 a.p. wk 1 p.p. wk 4 p.p. wk 14 p.p.

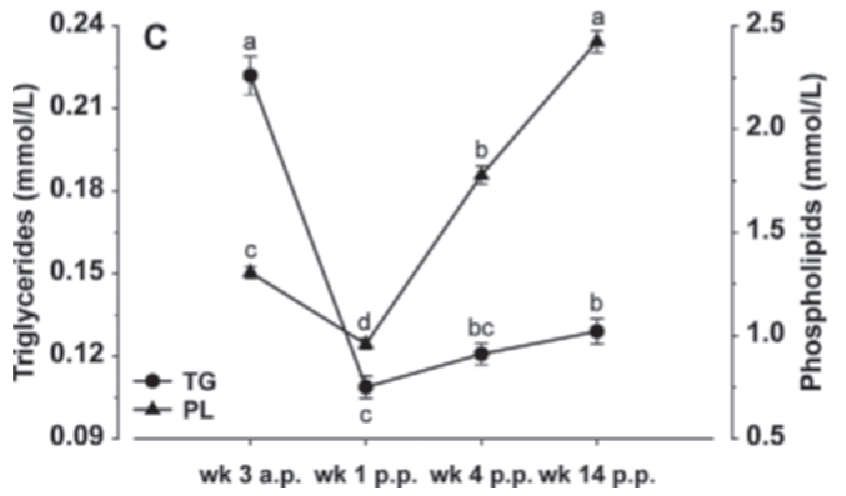

Figure 1. Plasma concentration of total cholesterol (TC), cholesteryl esters $(\mathrm{CE})$, and free cholesterol (FC; $\mathrm{A})$; very low density lipoprotein cholesterol (VLDL-C), low density lipoprotein cholesterol (LDL-C), and high density lipoprotein cholesterol (HDL-C; B); and triglycerides (TG) and phospholipids (PL; C) in cows from wk 3 antepartum (a.p.) to wk 14 postpartum (p.p.). Significant changes over time are marked with different letters $(\mathrm{a}-\mathrm{d} ; P<0.05)$. Data are shown as mean values \pm SEM.

showed an increase from wk 3 a.p. to wk 1 p.p. and remained thereafter on a comparable level, whereas the expression of $A B C G 1$ was increased in wk 14 p.p. compared with other time points (Table 2). The $H M G C R$ and HMGCS1 mRNA abundances increased markedly from wk 3 a.p. to the lactational period, whereas the hepatic mRNA abundance of MTTP was not different between the measured time points (Table 2).

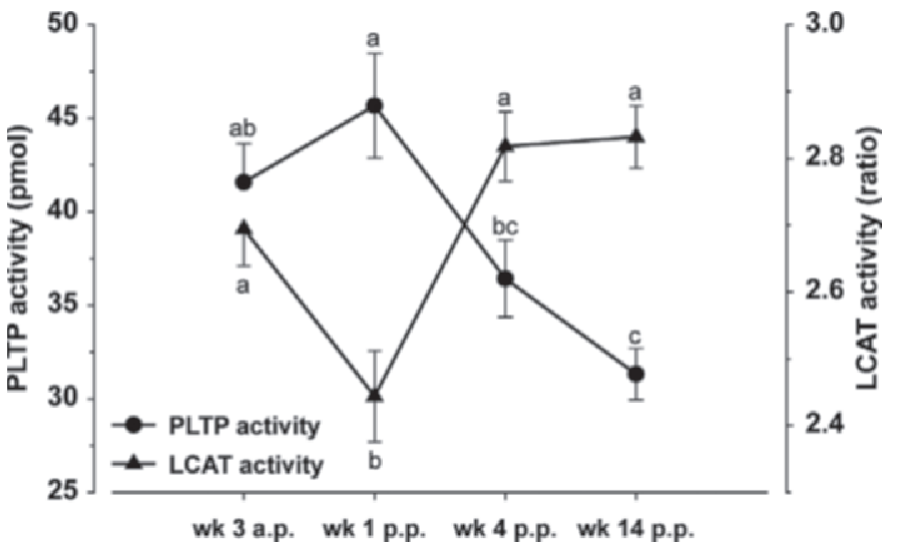

Figure 2. Plasma activity of phospholipid transfer protein (PLTP) and lecithin:cholesterol acyltransferase (LCAT) in cows from wk 3 antepartum (a.p.) to wk 14 postpartum (p.p.). The LCAT activity is assessed as a ratio of the emissions of the substrate hydrolyzed to that not hydrolyzed. Significant changes over time are marked with different letters $(\mathrm{a}-\mathrm{c} ; P<0.05)$. Data are shown as mean values $\pm \mathrm{SEM}$.

No differences in the hepatic expression of $L X R \alpha$, $P P A R \alpha$, and PPAR $\gamma$ were found over time (Table 2). The mRNA abundance of $S R E B F-1$ was lowest in wk 1 p.p. compared with other time points, whereas the mRNA abundance of SREBF-2 increased from wk 3 a.p. to wk 1 p.p. (Table 2).

\section{DISCUSSION}

In dairy cows, the transition period from the nonlactating to the lactating state requires important homeorhetic changes (Bauman and Currie, 1980) to enable the shift of nutrients from body stores toward the mammary gland for milk production. In this context, not only glucose and lipid metabolism have to adapt to the lactating state, but also cholesterol metabolism. Thus, the aim of the present study was to comprehensively investigate different compartments, regulatory components, and interactions mediating cholesterol homeostasis in dairy cows during the transition period until mid lactation.

3-Hydroxy-3-methylglutaryl-CoA reductase and HMGCS1 are key enzymes of the cholesterol biosynthetic pathway and act as rate-controlling steps, with HMGCS producing the substrate for the HMGCR reaction (Horton et al., 1998). In agreement with other studies (van Dorland et al., 2009; Viturro et al., 2009), $H M G C R$ and HMGCS1 were markedly upregulated during early lactation compared with late pregnancy. The synthesis of sterols is controlled by SREBF-2 (Horton et al., 1998). Sterol regulatory element-binding factors are synthesized as endoplasmic reticulum membrane proteins. In the case of low cholesterol levels, 
Table 2. Relative mRNA abundance $\left[\Delta\right.$ cycle threshold $\left.(\mathrm{CT}), \log _{2}\right]$ of genes analyzed in liver biopsies ${ }^{1}$

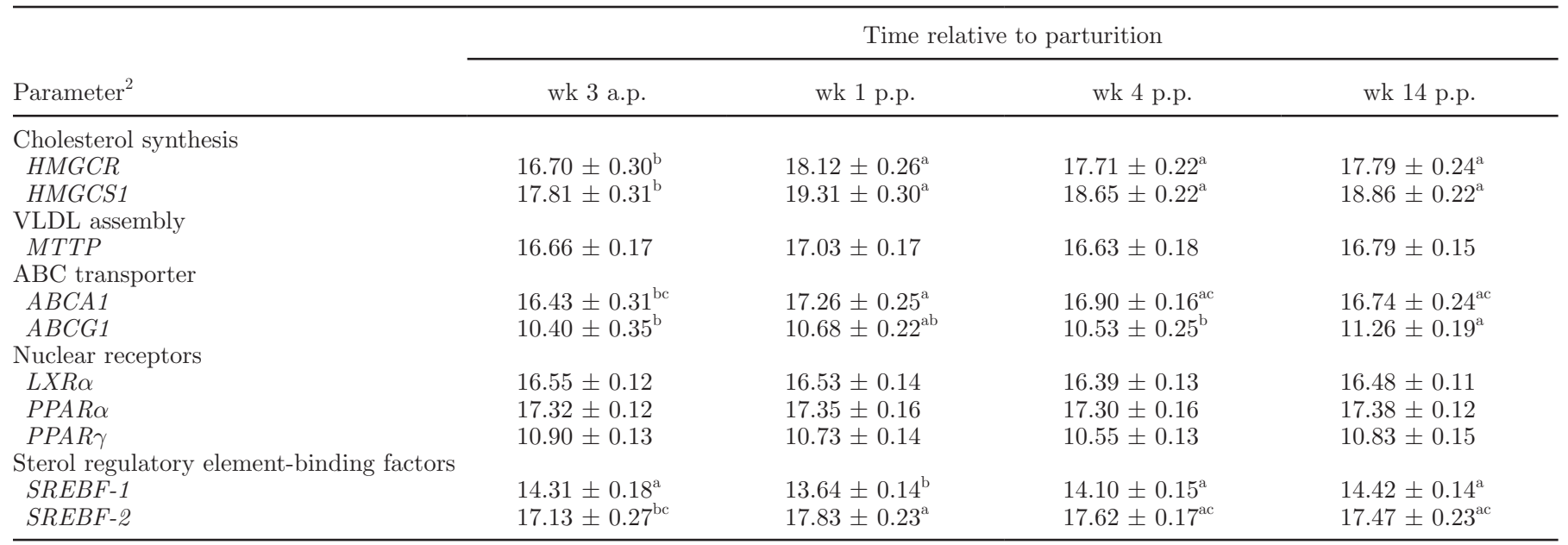

${ }^{\mathrm{a}-\mathrm{c}}$ Values within a row with different superscript letters are significantly different $(P<0.05)$.

${ }^{1}$ Hepatic mRNA expression was analyzed in wk 3 antepartum (a.p.), wk 1 postpartum (p.p.), wk 4 p.p., and wk 14 p.p. Data are presented as means \pm SEM.

${ }^{2} H M G C R=3$-hydroxy-3-methylglutaryl-CoA reductase; HMGCS1 = 3-hydroxy-3-methylglutaryl-CoA synthase 1; VLDL = very low density lipoprotein; $M T T P=$ microsomal triglyceride transfer protein; $A B C A 1=\mathrm{ATP}$-binding cassette transporter A1; $A B C G 1=\mathrm{ATP}$-binding cassette transporter G1; $L X R \alpha=$ liver X receptor $\alpha ; P P A R \alpha=$ peroxisome proliferator-activated receptor $\alpha$; $P P A R \gamma=$ peroxisome proliferatoractivated receptor $\gamma ; S R E B F-1=$ sterol regulatory element-binding factor $1 ; S B R E F-2=$ sterol regulatory element-binding factor 2 .

they migrate to the Golgi apparatus where they are cleaved and then released as nuclear SREBF able to activate target genes (Desvergne et al., 2006; Daemen et al., 2013). During this translocation, posttranscriptional modifications of SREBF take place that might affect their further effects besides the mRNA expression level. In the present study, a significant increase in SREBF-2 mRNA abundance from pregnancy to the onset of lactation was observed emphasizing the regulatory function of SREBF-2 in cholesterol biosynthesis. Furthermore, SREBF-2 mRNA expression showed high and significant correlations with the hepatic gene expressions of HMGCR and HMGCS1 (data not shown).

Despite the apparently enhanced cholesterol synthesis machinery at the onset of lactation, both TC concentration and individual lipoprotein-associated cholesterol fractions in the plasma (VLDL-C, LDL-C, and HDL-C) were dramatically decreased. Very low density lipoproteins are the most important carriers of TG in blood (Bauchart, 1993). During the early lactational negative energy balance, body fat reserves are mobilized and NEFA are transported to the liver where they are either oxidized or reesterified to TG. For the export from the liver, TG are packed in VLDL. MTTP is required for TG accumulation and apolipoprotein (apo) B lipidation during the assembly of VLDL (Kulinski et al., 2002). In the present study, hepatic mRNA abundance of MTTP was not affected during the entire experimental period, in contrast to an earlier study (Schlegel et al., 2012) where an increased expression of MTTP in wk 1 p.p. was observed. In the current investigation, and in agreement with Van den Top et al. (2005), VLDL-C and TG concentrations in plasma were distinctly decreased after parturition. Therefore, the secretion of VLDL from the liver might be limited at the onset of lactation and TG accumulate in the liver, leading to fatty liver, as confirmed by Gross et al. (2013).

Loor et al. (2007) hypothesized that cholesterol might be the limiting parameter of VLDL synthesis. However, the upregulation of the enzymes involved in cholesterol synthesis found in the present study as well as the high liver cholesterol concentration reported previously (Schlegel et al., 2012) suggest that this is unlikely. Furthermore, the upregulation of the $H M G C R$ and HMGCS1 genes may be interpreted as a physiological reaction to guarantee sufficient cholesterol supply for the production of VLDL; thus, enabling the export of TG from the liver. Van den Top et al. (1996) proposed PL as the limiting factor for VLDL secretion, as, consistent with the present study, a decreased plasma concentration of PL was found after parturition. Moreover, the limited ability of ruminant hepatocytes to secrete VLDL (Kleppe et al., 1988; Pullen et al., 1990) may also contribute to the accumulation of TG in the liver.

In agreement with Van den Top et al. (2005), the LDL-C plasma concentration was decreased after parturition and steadily increased thereafter. The low plasma LDL-C concentration at the onset of lacta- 

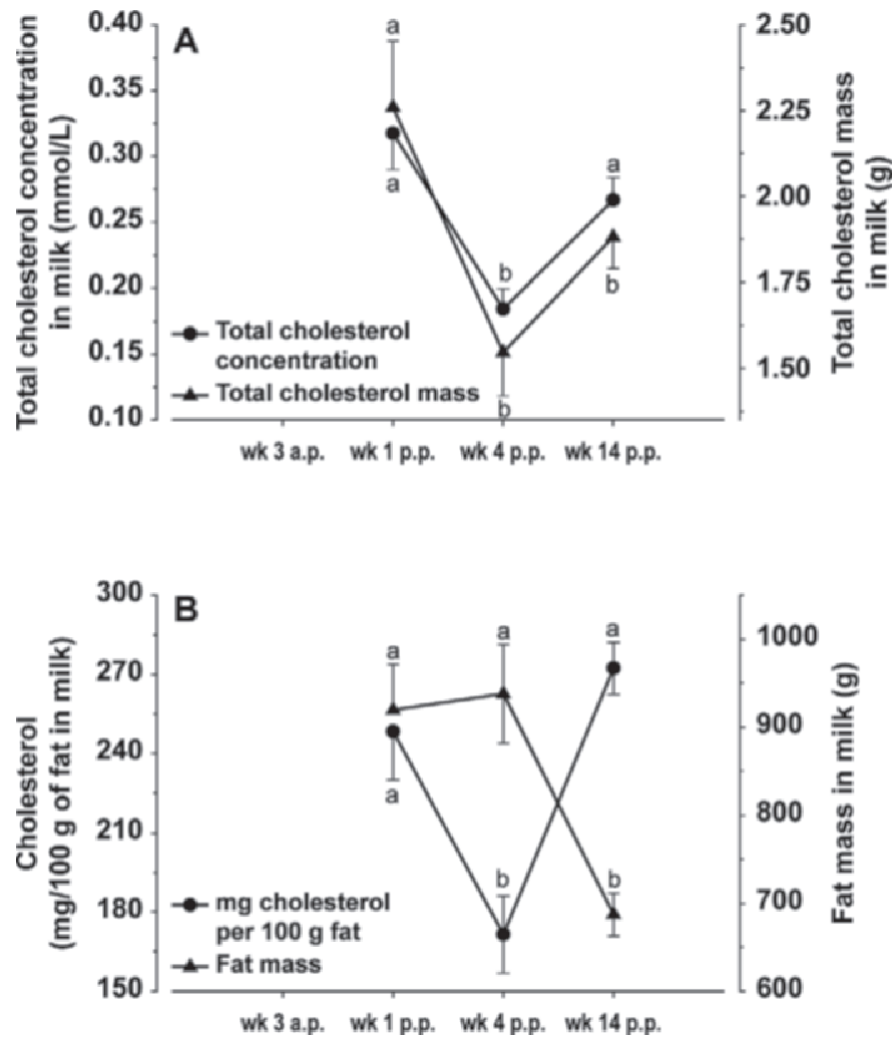

Figure 3. Total cholesterol concentration and mass (g) in milk (A) and cholesterol concentration in milk fat ( $\mathrm{mg}$ of cholesterol per $100 \mathrm{~g}$ of fat) and mass ( $\mathrm{g}$ ) of fat in milk (B) in cows from wk 1 postpartum (p.p.) to wk 14 p.p. Significant changes over time are marked with different letters ( $\mathrm{a}$ and $\mathrm{b} ; P<0.05$ ). Data are shown as mean values \pm SEM. a.p. $=$ antepartum.

tion might be a consequence of the low export rate of VLDL by the liver, as LDL arise from VLDL by receiving cholesteryl esters. Beside LDL-C, CE and FC plasma concentrations were lowest in the first week after parturition, and the cholesteryl esters:TC ratio was also decreased at the onset of lactation (data not shown) in line with a diminished activity of LCAT. Lecithin:cholesterol acyltransferase catalyzes the esterification of FC taken up from extrahepatic tissues by HDL with lecithin to produce cholesteryl esters. The reduced LCAT activity shortly after parturition was initially hypothesized to be a consequence of naturally occurring fatty liver (Nakagawa et al., 1997), but was also found in healthy cows with no fat infiltration of the liver (Pösö et al., 2000). Dairy cows included in the present study were attributed a "moderate fatty liver" (Gross et al., 2013) according to the classification given in Bobe et al. (2004). Thus, the decreased LCAT activity in this study at the onset of lactation might occur physiologically and could be additionally enforced by the development of fatty liver.
Phospholipid transfer protein has different physiological functions, such as promoting the net transfer of phospholipids from VLDL toward HDL (Tall et al., 1985). Phosphatidylcholines, a class of phospholipids, are the essential cholesterol-solubilizing components of HDL and the acyl donors for the esterification of FC into CE by LCAT (Rao et al., 1997). The elevated plasma PLTP activity during the negative energy balance in early lactation could represent a physiological reaction to counteract the low plasma cholesterol concentration by providing substrate for the LCAT reaction and thereby increasing the $\mathrm{CE}$ production in plasma. Oram et al. (2003) demonstrated that PLTP can mimic HDL apolipoproteins in removing cholesterol and phospholipids from cells by the ABCA1 pathway. The low plasma concentrations of TC and PL could, therefore, trigger the mobilization of cholesterol and PL by PLTP.

Cholesterol is transported from peripheral tissues to the liver by HDL. Nascent HDL particles are formed in the liver by the lipidation of apo A-I by the ABCA1 pathway (Vaughan and Oram, 2006). Adenosine triphosphate-binding cassette transporter A1 plays a critical role in the efflux of cellular cholesterol to apo A-I (Oram and Heinecke, 2005). In the present study, the hepatic gene expression of $A B C A 1$ was upregulated in wk 1 p.p. compared with late pregnancy, in agreement with Schlegel et al. (2012). However, the upregulation of the $A B C A 1$ gene was not reflected by an increased HDL-C concentration in plasma, as the latter decreased to a minimum at the onset of lactation. In general, the low HDL-C levels could have different reasons, such as decreased reverse cholesterol transport from extrahepatic tissues to the liver or a higher uptake rate of HDL-C via the hepatic scavenger receptor class B type I (SR-BI) receptor. The upregulation of $A B C A 1$ mRNA at the onset of lactation in the present study indicates that the ABCA1-mediated initiation of reverse cholesterol transport is not impaired (given that $A B C A 1 \mathrm{mRNA}$ expression and protein activity correspond). Thus, it is likely that the HDL-C levels in the plasma are reduced due to either lower production of HDL-C from extrahepatic tissues, including other factors important for reverse cholesterol transport or higher clearance of HDL-C from the liver. Adenosine triphosphate-binding cassette transporter G1 is also involved in the export of cellular cholesterol and was shown to act in concert with ABCA1 to maximize the removal of excess cholesterol from cells (Vaughan and Oram, 2006). In contrast to $A B C A 1$, the hepatic mRNA abundance of $A B C G 1$ was elevated in mid lactation compared with earlier time points, a finding which was confirmed by a recent study (Schlegel et al., 2012). Thus, despite exerting similar physiological functions, the 2 cholesterol efflux proteins seem to be affected and 
differentially regulated by the lactational stage. This could indicate that ABCA1 and ABCG1 may either have different functions during the pregnancy-lactation cycle and (or) that factors specific for the respective lactational stage differentially regulate their expression pattern in dairy cows. The molecular identity of these factors is currently unclear but it could be speculated that differential hormonal regulation or a potentially different apolipoprotein profile during the pregnancylactation cycle may play a role.

Adenosine triphosphate-binding cassette transporter A1 and $A B C G 1$ are target genes of the nuclear receptor LXR $\alpha$. Liver X receptor $\alpha$ functions as a sensor of cholesterol levels and is able to enhance the removal of cholesterol from cells by induction of ABC transporters (Schwartz et al., 2000; Desvergne et al., 2006). However, the mRNA abundance of $L X R \alpha$ was not altered between late pregnancy and lactation. Thus, other regulatory mechanisms than LXR $\alpha$ are involved in the regulation of the $\mathrm{ABC}$ transporters investigated in the present study. A regulating role could be assigned to $S R E B F$-2, as this gene was highly correlated with both $A B C A 1$ and $A B C G 1$ expression (data not shown). In this context, also PPAR $\alpha$ and $\gamma$ were analyzed. Peroxisome proliferator-activated receptor $\alpha$ is involved in hepatic lipid catabolism through the activation of the $\beta$-oxidation pathway of NEFA in peroxisomes and mitochondria (Desvergne et al., 2006). In the present study, the mRNA abundance of PPAR $\alpha$ was not affected during the entire experimental period, even though cows had high plasma NEFA levels during early lactation (Gross et al., 2011a). In the study of van Dorland et al. (2009) the expression of PPAR $\alpha$ did also not change, which was explained by the absence of a plasma NEFA peak, as Loor et al. (2005) had observed an upregulation of $P P A R \alpha$ together with high NEFA concentrations. The mRNA abundance of $P P A R \gamma$, a transcription factor that plays an adipogenic role in adipose tissue and to a lesser degree also in the liver (Desvergne and Wahli, 1999), was also unaffected by the lactational stage in the present investigation.

Another key factor in the hepatic transcriptional regulation of lipogenic enzymes is SREBF-1. Sterol regulatory element-binding factor 1 activates several genes involved in FA synthesis, such as acetyl-CoA carboxylase $(A C C)$ or FA synthase (FASN; Shimano et al., 1999). At the onset of lactation, the cows included in the present study experienced a hypoinsulinemic state (Gross et al., 2011b), and SREBF-1 was downregulated. Downregulation of $S R E B F-1$ during early lactation was also observed by Graber et al. (2010) and is reflected by a reduced expression of $A C C$ and $F A S N$ in the peripartal period (Gross et al., 2013). Sterol regulatory element-binding factor 1, in contrast to SREBF-2, is known to be stimulated by insulin, as both SREBF-1 and insulin have been shown to induce lipogenesis (Daemen et al., 2013). Furthermore, insulin upregulates HMGCR in vitro (Bhasker and Friedmann, 2008) and, in diabetic rats, insulin was able to restore the decreased HMGCR levels (Ness et al., 1994). However, these findings seem not to be applicable to dairy cows, as $H M G C R$ and $H M G C S 1$ were markedly upregulated after parturition, whereas the plasma insulin concentration was decreased (Gross et al., 2011b).

In dairy cows, the hypoinsulinemic state at the onset of lactation enables more glucose uptake by the mammary gland (Bauman and Elliot, 1983). Apart from lactose, the main energy source for the offspring in milk are lipids. Most lipids are TG (97-98\%), whereas PL (ca. 1\%) and cholesterol (ca. 0.5\%) represent just a small percentage that varies at different stages of lactation (Bitman and Wood, 1990; Jensen, 2002; Ontsouka and Albrecht, 2014). In agreement, TC concentration in milk was higher in wk 1 p.p. compared with wk 4 p.p. This was not a consequence of a higher dilution factor because of increasing milk yields, as also the mass of cholesterol transferred into milk was increased. The higher amount of cholesterol in the fat fraction in wk 1 p.p. compared with wk 4 p.p. can be explained by an elevated fat content in wk 4 p.p. in parallel to low cholesterol levels. Interestingly, the cholesterol concentration in milk reached its highest levels in wk 1 p.p. while in that period it was concomitantly lowest in blood. Only a small part of milk cholesterol originates from de novo synthesis in the mammary gland, whereas cholesterol uptake from the blood is far more pronounced (Long et al., 1980). It is likely that the high cholesterol mass in milk in wk 1 p.p. is partly responsible for the low cholesterol concentration in the blood. However, the elevated cholesterol mass in milk at the onset of lactation may be due to an increased apoptosis of mammary epithelial cells (MEC) in the mammary gland. Mani et al. (2009) reported an upregulation of $A B C A 1$ mRNA in mammary tissue at the end of the dry period compared with d 42 p.p., suggesting potential involvement of this transporter in the removal of cholesterol from MEC by efflux into milk. Mammary epithelial cell apoptosis is increased during late pregnancy and at the onset of lactation, leading to an accumulation of cholesterolrich debris in MEC (Annen et al., 2007; Mani et al., 2009). Thus, the high cholesterol mass in milk during the first week of lactation might be supported by an increased efflux of cholesterol from the mammary gland by ABCA1. Furthermore, the localization pattern of the ABCA1 protein in MEC seems to depend on the functional stage of the mammary gland (Mani et al., 2009; Mani et al., 2011). Thus, the varying localization of ABCA1 during the pregnancy-lactation cycle may 
affect the cholesterol mass in milk at different stages of lactation.

\section{CONCLUSIONS}

The present comprehensive study investigates the interactions between cholesterol metabolism and transport at different functional levels and gives novel insights into the complex network of regulatory mechanisms that are affected by the physiological stage of the dairy cow. At the onset of lactation, the hepatic gene expressions of key enzymes of cholesterol biosynthesis are upregulated to meet the increased cholesterol requirements for exporting liver TG in the lactating dairy cow. However, the changes in hepatic gene expression are not reflected by an increase in the concentrations of lipoproteins and their components (TG, cholesterol, and PL) in plasma. These results indicate that the liver responds at the gene expression level accurately to the increased demand at the onset of lactation. Whether the low cholesterol and TG plasma levels are due to a compromised export rate from the liver, or represent a consequence of the increased transfer of these essential nutrients into milk for the offspring remains to be elucidated.

\section{ACKNOWLEDGMENTS}

E. C. Kessler was supported by a scholarship of the H. Wilhelm Schaumann-Stiftung (Hamburg, Germany). C. Albrecht was supported by the Swiss National Center of Competence in Research (NCCR) TransCure (University of Bern, Bern, Switzerland).

\section{REFERENCES}

Annen, E. L., A. C. Fitzgerald, P. C. Gentry, M. A. McGuire, A. V. Capuco, L. H. Baumgard, and R. J. Collier. 2007. Effect of continuous milking and bovine somatotropin supplementation on mammary epithelial cell turnover. J. Dairy Sci. 90:165-183.

Bauchart, D. 1993. Lipid absorption and transport in ruminants. J. Dairy Sci. 76:3864-3881.

Bauman, D. E., and W. B. Currie. 1980. Partitioning of nutrients during pregnancy and lactation: A review of mechanisms involving homeostasis homeorhesis. J. Dairy Sci. 63:1514-1529.

Bauman, D. E., and J. W. Elliot. 1983. Control of nutrient partitioning in lactating ruminants. Pages 437-468 in Biochemistry of Lactation. T. B. Mepham, ed. Elsevier Science Publishers, Amsterdam, the Netherlands.

Bhasker, C. R., and T. Friedmann. 2008. Insulin-like growth factor-1 coordinately induces the expression of fatty acid and cholesterol biosynthetic genes in murine $\mathrm{C} 2 \mathrm{C} 12$ myoblasts. BMC Genomics 9:535.

Bitman, J., and D. L. Wood. 1990. Changes in milk fat phospholipids during lactation. J. Dairy Sci. 73:1208-1216.

Bobe, G., J. W. Young, and D. C. Beitz. 2004. Invited review: Pathology, etiology, prevention, and treatment of fatty liver in dairy cows. J. Dairy Sci. 87:3105-3124.

Daemen, S., M. Kutmon, and C. T. Evelo. 2013. A pathway approach to investigate the function and regulation of SREBPs. Genes Nutr. 8:289-300.
Desvergne, B., L. Michalik, and W. Wahli. 2006. Transcriptional regulation of metabolism. Physiol. Rev. 86:465-514.

Desvergne, B., and W. Wahli. 1999. Peroxisome proliferator-activated receptors: Nuclear control of metabolism. Endocr. Rev. 20:649 688

Friedewald, W. T., R. I. Levy, and D. S. Fredrickson. 1972. Estimation of the concentration of low-density lipoprotein cholesterol in plasma, without use of the preparative ultracentrifuge. Clin. Chem. 18:499-502

Goff, J. P., and R. L. Horst. 1997. Physiological changes at parturition and their relationship to metabolic disorders. J. Dairy Sci. 80:1260-1268.

Graber, M., S. Kohler, T. Kaufmann, M. G. Doherr, R. M. Bruckmaier, and H. A. van Dorland. 2010. A field study on characteristics and diversity of gene expression in the liver of dairy cows during the transition period. J. Dairy Sci. 93:5200-5215.

Gross, J., H. A. van Dorland, R. M. Bruckmaier, and F. J. Schwarz. 2011a. Performance and metabolic profile of dairy cows during a lactational and deliberately induced negative energy balance by feed restriction with subsequent realimentation. J. Dairy Sci. 94:1820-1830.

Gross, J., H. A. van Dorland, F. J. Schwarz, and R. M. Bruckmaier. 2011b. Endocrine changes and liver mRNA abundance of somatotropic axis and insulin system constituents during negative energy balance at different stages of lactation in dairy cows. J. Dairy Sci. 94:3484-3494.

Gross, J. J., F. J. Schwarz, K. Eder, H. A. van Dorland, and R. M. Bruckmaier. 2013. Liver fat content and lipid metabolism in dairy cows during early lactation and during a mid-lactation feed restriction. J. Dairy Sci. 96:5008-5017.

Grummer, R. R. 1993. Etiology of lipid-related metabolic disorders in periparturient dairy cows. J. Dairy Sci. 76:3882-3896.

Horton, J. D., I. Shimomura, M. S. Brown, R. E. Hammer, J. L. Goldstein, and H. Shimano. 1998. Activation of cholesterol synthesis in preference to fatty acid synthesis in liver and adipose tissue of transgenic mice overproducing sterol regulatory element-binding protein-2. J. Clin. Invest. 101:2331-2339.

Jensen, R. G. 2002. Invited review: The composition of bovine milk lipids: January 1995 to December 2000. J. Dairy Sci. 85:295-350.

Kamelska, A. M., R. Pietrzak-Fiećko, and K. Bryl. 2012. Variation of the cholesterol content in breast milk during 10 days collection at early stages of lactation. Acta Biochim. Pol. 59:243-247.

Kleppe, B. B., R. J. Aiello, R. R. Grummer, and L. E. Armentano. 1988. Triglyceride accumulation and very low density lipoprotein secretion by rat and goat hepatocytes in vitro. J. Dairy Sci. 71:1813-1822.

Kulinski, A., S. Rustaeus, and J. E. Vance. 2002. Microsomal triacylglycerol transfer protein is required for lumenal accretion of triacylglycerol not associated with ApoB, as well as for ApoB lipidation. J. Biol. Chem. 277:31516-31525.

Long, C. A., S. Patton, and R. D. McCarthy. 1980. Origins of the cholesterol in milk. Lipids 15:853-857.

Loor, J. J., R. E. Everts, M. Bionaz, H. M. Dann, D. E. Morin, R. Oliveira, S. L. Rodriguez-Zas, J. K. Drackley, and H. A. Lewin. 2007. Nutrition-induced ketosis alters metabolic and signaling gene networks in liver of periparturient dairy cows. Physiol. Genomics 32:105-116.

Loor, J. J., R. E. Everts, R. Oliveira, C. A. Green, N. A. Guretzky, S. L. Rodriguez-Zas, H. A. Lewin, and J. K. Drackley. 2005. Temporal gene expression profiling of liver from periparturient dairy cows reveals complex adaptive mechanisms in hepatic function. Physiol. Genomics 23:217-226.

Mani, O., M. Körner, C. E. Ontsouka, M. T. Sorensen, K. Sejrsen, R. M. Bruckmaier, and C. Albrecht. 2011. Identification of ABCA1 and ABCG1 in milk fat globules and mammary cells-Implications for milk cholesterol secretion. J. Dairy Sci. 94:1265-1276.

Mani, O., M. T. Sorensen, K. Sejrsen, R. M. Bruckmaier, and C. Albrecht. 2009. Differential expression and localization of lipid transporters in the bovine mammary gland during the pregnancylactation cycle. J. Dairy Sci. 92:3744-3756. 
Maxfield, F. R., and I. Tabas. 2005. Role of cholesterol and lipid organization in disease. Nature 438:612-621.

Nakagawa, H., S. Oikawa, T. Oohashi, and N. Katoh. 1997. Decreased serum lecithin-cholesterol acyltransferase activity in spontaneous cases of fatty liver in cows. Vet. Res. Commun. 21:1-8.

Ness, G. C., Z. Zhao, and L. Wiggins. 1994. Insulin and glucagon modulate hepatic 3-hydroxy-3-methylglutaryl-coenzyme A reductase activity by affecting immunoreactive protein levels. J. Biol. Chem. 269:29168-29172.

Ontsouka, E. C., and C. Albrecht. 2014. Cholesterol transport and regulation in the mammary gland. J. Mammary Gland Biol. Neoplasia 19:43-58.

Oram, J. F., and J. W. Heinecke. 2005. ATP-binding cassette transporter A1: A cell cholesterol exporter that protects against cardiovascular disease. Physiol. Rev. 85:1343-1372.

Oram, J. F., G. Wolfbauer, A. M. Vaughan, C. Tang, and J. J. Albers. 2003. Phospholipid transfer protein interacts with and stabilizes ATP-binding cassette transporter A1 and enhances cholesterol efflux from cells. J. Biol. Chem. 278:52379-52385.

Paradkar, M. M. and J. Irudayaraj. 2002. Determination of cholesterol in dairy products using infrared techniques: 1. FTIR spectroscopy. Int. J. Dairy Technol. 55:127-132.

Pösö, A. R., T. M. Saukko, A. T. Tesfa, and L.-A. Lindberg. 2000. Fat infiltration in liver and activity of lecithin:cholesterol acyltransferase in serum of dry and lactating dairy cows. Res. Vet. Sci. 68:169-173.

Pullen, D. L., J. S. Liesman, and R. S. Emery. 1990. A species comparison of liver slice synthesis and secretion of triacylglycerol from nonesterified fatty acids in media. J. Anim. Sci. 68:1395-1399.

Puppione, D. L., N. E. Smith, C. K. Clifford, and A. J. Clifford. 1980. Relationships among serum lipids, milk production and physiological status in dairy cows. Comp. Biochem. Physiol. Part A Physiol. 65:319-323.

Rao, R., J. J. Albers, G. Wolfbauer, and H. J. Pownall. 1997. Molecular and macromolecular specificity of human plasma phospholipid transfer protein. Biochemistry 36:3645-3653.

Raphael, B. C., P. S. Dimick, and D. L. Puppione. 1973. Lipid characterization of bovine serum lipoproteins throughout gestation and lactation. J. Dairy Sci. 56:1025-1032.
Schlegel, G., R. Ringseis, J. Keller, F. J. Schwarz, and K. Eder. 2012 Changes in the expression of hepatic genes involved in cholesterol homeostasis in dairy cows in the transition period and at different stages of lactation. J. Dairy Sci. 95:3826-3836.

Schwartz, K., R. M. Lawn, and D. P. Wade. 2000. ABC1 gene expression and ApoA-I-mediated cholesterol efflux are regulated by LXR. Biochem. Biophys. Res. Commun. 274:794-802.

Shimano, H., N. Yahagi, M. Amemiya-Kudo, A. H. Hasty, J. Osuga, Y. Tamura, F. Shionoiri, Y. Iizuka, K. Ohashi, K. Harada, T. Gotoda, S. Ishibashi, and N. Yamada. 1999. Sterol regulatory element-binding protein-1 as a key transcription factor for nutritional induction of lipogenic enzyme genes. J. Biol. Chem. 274:35832-35839.

Tall, A. R., S. Krumholz, T. Olivecrona, and R. J. Deckelbaum. 1985. Plasma phospholipid transfer protein enhances transfer and exchange of phospholipids between very low density lipoproteins and high density lipoproteins during lipolysis. J. Lipid Res. 26:842851.

Van den Top, A. M., M. J. Geelen, T. Wensing, G. H. Wentink, A. T. Van 't Klooster, and A. C. Beynen. 1996. Higher postpartum hepatic triacylglycerol concentrations in dairy cows with free rather than restricted access to feed during the dry period are associated with lower activities of hepatic glycerolphosphate acyltransferase. J. Nutr. 126:76-85.

Van den Top, A. M., A. Van Tol, H. Jansen, M. J. H. Geelen, and A. C. Beynen. 2005. Fatty liver in dairy cows post partum is associated with decreased concentration of plasma triacylglycerols and decreased activity of lipoprotein lipase in adipocytes. J. Dairy Res. 72:129-137.

van Dorland, H. A. S. Richter, I. Morel, M. G. Doherr, N. Castro, and R. M. Bruckmaier. 2009. Variation in hepatic regulation of metabolism during the dry period and in early lactation in dairy cows. J. Dairy Sci. 92:1924-1940.

Vaughan, A. M., and J. F. Oram. 2006. ABCA1 and ABCG1 or ABCG4 act sequentially to remove cellular cholesterol and generate cholesterol-rich HDL. J. Lipid Res. 47:2433-2443.

Viturro, E., M. Koenning, A. Kroemer, G. Schlamberger, S. Wiedemann, M. Kaske, and H. H. D. Meyer. 2009. Cholesterol synthesis in the lactating cow: Induced expression of candidate genes. J. Steroid Biochem. Mol. Biol. 115:62-67. 